\title{
INDOCYANINE GREEN CLEARANCE RATE AS A PREDICTIVE FACTOR OF COMPLICATIONS FOLLOWING MAJOR LIVER RESECTION
}

Bono, P.; Narváez, J.; Alarcón, L.; Olmedilla, L.; Pérez, J.M.; Duque, P.

\section{GOAL OF STUDY}

Indocyanine green elimination by pulse spectrophotometry is a non-invasive liver function monitoring system.

$>$ The aim of this study is to assess the relationship between postoperative ICG plasma disappearance rate (ICG PDR \% min) and the onset of medical and surgical complications.

\section{MATERIALS AND METHODS}

33 patients scheduled for mayor liver resection were selected. ICG PDR was measured preoperatively and on the day 1 and 2 postoperative. We recorded the appearance of surgical complications postoperatively (liver ischemia, biliary leak and intra-abdominal fluid collections and medical complications (pneumonia, ascites, pleural effusion, infection, coagulopathy and thrombosis) All the patients were included after

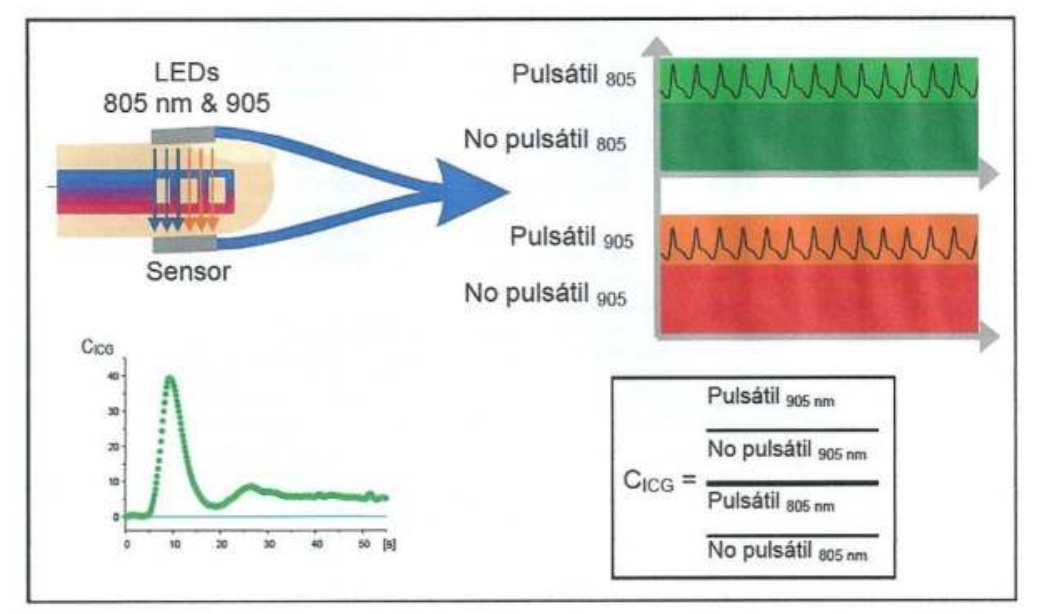
signing an Informed Consent

\section{RESULTS}

7 patients underwent surgical complications and 14 medical ones. When analyzing the surgical complications, PDR the first day was mayor in the group that did not develop any events 18,4 \pm 6 against 11,3 \pm 7 in the group with surgical issues ( $p$ ng medical events, first day PDR was $19 \pm 6$ in the patients with no issues versus $13 \pm 5$ in the group that had any medical complication. Moreover, our results show a significative association between PDR measurement taken on postoperative day 1 and hospital stay $(r=-0,46 p=0,01)$ and ICU stay $(r=-0,37 p=0,03)$. No significative association was found between routine laboratory tests and adverse events occurrence.

\begin{tabular}{|l|l|l|l|}
\hline & $\begin{array}{l}\text { Complicaciones quirúrgicas } \\
\text { SI }\end{array}$ & $\begin{array}{l}\text { Complicaciones quirúrgicas } \\
\text { NO }\end{array}$ & significacion \\
\hline PDR basal mediana & 18,7 IQR 14,8-19,8 & 22,3 IQR 19,9-25,9 & 0,01 no Parametrica \\
\hline PDR 1er dia & $11 \pm 5$ & $18 \pm 6$ & 0,014 \\
\hline Coloides & $0 \pm 0$ & $200 \pm 237$ & 0,04 no parametrica \\
\hline & & & \\
\hline Extem ML preq & $0,33 \pm 0,8$ & $4,21 \pm 3,4$ & 0,000 \\
\hline Extem ang alfa preq & $79 \pm 2$ & $71 \pm 11$ & 0,005 \\
\hline Intem ML preq & $0,5 \pm 1,2$ & $3,1 \pm 3,2$ & 0,009 \\
\hline Hb 1er dia & $9,4 \pm 0,8$ & $10,7 \pm 1,4$ & 0,01 \\
\hline Extem ML 1er dia & $0,43 \pm 1,1$ & $2,9 \pm 3,7$ & 0,049 no parametrica \\
\hline Intem MCF 1er dia & $68 \pm 6$ & $60 \pm 8$ & 0,045 \\
\hline
\end{tabular}

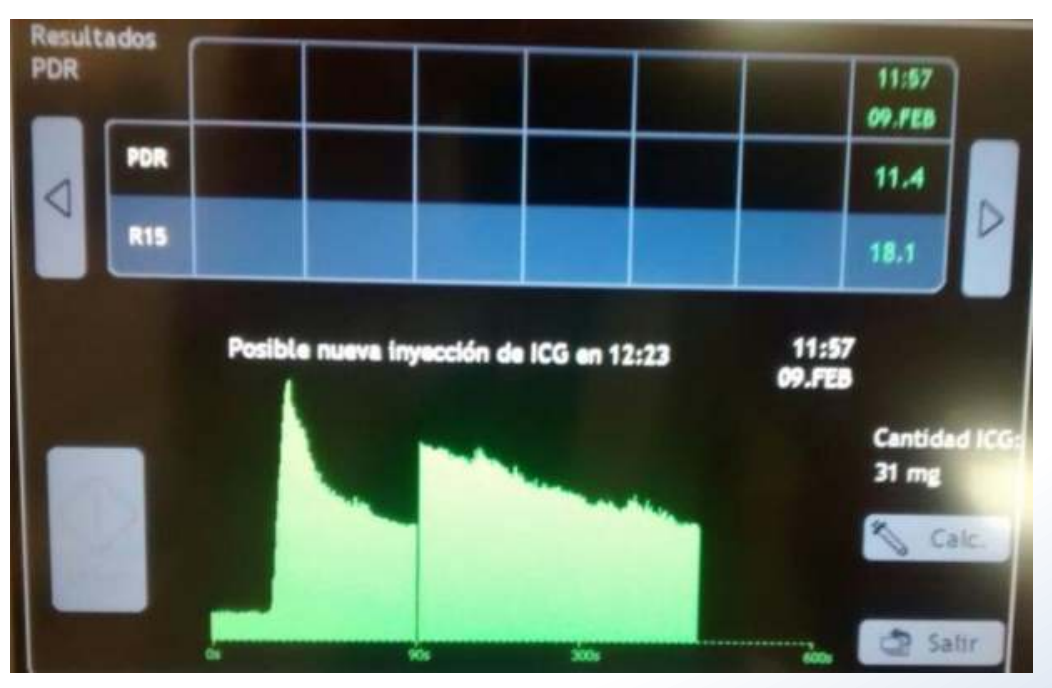

\section{CONCLUSIONS}

ICG PDR is a useful, non-invasive liver function test in patients undergoing major liver resection. It may help to predict both medical and surgical complications in these patients, improving their management and therefore, their outcome. 